\title{
Effects of Quercetin on Mushroom Tyrosinase and B16-F10 Melanoma Cells
}

\section{Isao Kubo*, Teruhiko Nitoda and Ken-ichi Nihei}

Department of Environmental Science, Policy and Management, University of California, Berkeley, CA 94720-3114, USA

* Author to whom correspondence should be addressed; E-mail: ikubo@berkeley.edu

Received: 12 April 2007; in revised form: 14 May 2007 / Accepted: 14 May 2007 / Published: 15 May 2007

\begin{abstract}
In searching for tyrosinase inhibitors from plants using L-3,4-dihydroxyphenylalanine ( $L$-DOPA) as a substrate, quercetin was found to be partially oxidized to the corresponding $o$-quinone under catalysis by mushroom tyrosinase (EC 1.14.18.1). Simultaneously, $L$-DOPA was also oxidized to dopaquinone and both $o$-quinones were further oxidized, respectively. The remaining quercetin partially formed adducts with dopaquinone through a Michael type addition. In general, flavonols form adducts with dopaquinone as long as their 3-hydroxyl group is free. Quercetin enhanced melanin production per cell in cultured murine B16-F10 melanoma cells, but this effect may be due in part to melanocytotoxicity. The concentration leading to $50 \%$ viable cells lost was established as $20 \mu \mathrm{M}$ and almost complete lethality was observed at $80 \mu \mathrm{M}$.
\end{abstract}

Keywords: Quercetin, mushroom tyrosinase, adducts, murine B16-F10 melanoma cells, cytotoxicity

\section{Introduction}

The oxidation of L-tyrosine to melanin catalyzed by tyrosinase is of considerable importance since melanin has many functions in human systems. Alterations in melanin synthesis occur in many disease states. Melanins play a crucial role in the absorption of free radicals generated within the cytoplasm and in shielding the host from various types of ionizing radiation. The hydroxylation of 
L-tyrosine, the initial step in melanin synthesis [1], is also the initial step in catecholamine synthesis. Melanoma specific anticarcinogenic activity is also being linked with tyrosinase activity [2]. Melanin pigments are also found in the mammalian brain. Tyrosinase may play a role in neuromelanin formation in the human brain, particularly in the substantia nigra [3].

A common flavonol, quercetin (1, Figure 1), was previously isolated as the principal tyrosinase inhibitor from the dried flower of Heterotheca inuloides Cass (Compositae), known as "arnica” in Mexico [4,5]. The same flavonol was also isolated from the fresh flower of Trixis michuacana var longifolia (D. Dow) C. Anderson (Compositae), known as "huipate floreado” in Mexico [6]. Quercetin was previously reported to inhibit the oxidation of L-3,4-dihydroxyphenylalanine (L-DOPA, 2) catalyzed by mushroom tyrosinase (EC 1.14.18.1) [5,7-10]. As long as the enzyme activity was monitored by measuring dopachrome formation at $475 \mathrm{~nm}$, no visible absorption at $475 \mathrm{~nm}$ was observed up to $20 \mathrm{~min}$. In addition to quercetin, its 3 -O-glycosides, isoquercitrin or quercetin 3-O-glucoside (3) and rutin or quercetin 3-O-rutinoside (4) were isolated from the same sources, but both neither inhibited the enzyme activity nor acted as a substrate [11]. Hence, quercetin was reported to inhibit the oxidation of $L$-DOPA catalyzed by mushroom tyrosinase [5]. The inhibitory activity was described to come from its ability to chelate copper in the enzyme, since the $\gamma$-pyrone moiety seemed to preferentially chelate copper [11]. Subsequently, quercetin was found to be oxidized to the rather stable protocatechuate intermediate in a preincubation experiment (with tyrosinase but without L-DOPA) [12]. The aim of this paper is to report the effects of quercetin on the mushroom tyrosinase catalyzed oxidation of L-DOPA and murine B16-F10 melanoma cells.

Figure 1. Structures of quercetin (1) and related compounds.<smiles>[R5]c1cc([R4])c2c(=O)c([R3])c(-c3ccc([R])c([R2])c3)oc2c1</smiles>

1: $\mathrm{R}_{1}=\mathrm{R}_{2}=\mathrm{R}_{3}=\mathrm{R}_{4}=\mathrm{R}_{5}=\mathrm{OH}$

3: $\mathrm{R}_{1}=\mathrm{R}_{2}=\mathrm{R}_{4}=\mathrm{R}_{5}=\mathrm{OH}, \mathrm{R}_{3}=\mathrm{O}$-glucoside

4: $\mathrm{R}_{1}=\mathrm{R}_{2}=\mathrm{R}_{4}=\mathrm{R}_{5}=\mathrm{OH}, \mathrm{R}_{3}=$ O-rutinoside

11: $R_{1}=R_{2}=H, R_{3}=R_{4}=R_{5}=O H$

12: $R_{1}=R_{2}=R_{3}=H, R_{4}=R_{5}=O H$

13: $R_{1}=R_{4}=R_{5}=O H, R_{2}=R_{3}=H$

14: $R_{1}=R_{2}=R_{4}=R_{5}=H, R_{3}=O H$

15: $R_{1}=R_{2}=R_{5}=H, R_{3}=R_{4}=O H$

16: $R_{1}=R_{2}=R_{4}=H, R_{3}=R_{5}=O H$

17: $R_{1}=R_{3}=O H, R_{2}=R_{4}=R_{5}=H$

18: $R_{1}=R_{4}=O H, R_{2}=R_{3}=R_{5}=H$

21: $R_{1}=R_{2}=R_{3}=R_{4}=H, R_{5}=O H$<smiles>[NH3+][C@@H](Cc1ccc(O)c(O)c1)C(=O)[O-]</smiles>

2<smiles>O=C1C[C@H](c2ccc(O)cc2)Oc2cc(O)cc(O)c21</smiles>

19<smiles>O=C1C=C2C[C@H](C(=O)[O-])[NH+]2C=C1O</smiles>

5<smiles>O=c1cc(CO)occ1O</smiles>

20

\section{Results and Discussion}

In the previous papers, the tyrosinase activity was monitored by measuring at $475 \mathrm{~nm}$ the dopachrome (5) formation accompanying the oxidation of $L$-DOPA. Dopachrome is a relatively stable intermediate but is gradually oxidized further and therefore the spectrophotometric assay measures 
only the very initial rate of dopachrome formation to avoid involvement the secondary reaction [13]. The inhibition kinetic data are usually obtained within $1 \mathrm{~min}$, since the amount of dopachrome further decomposing within $1 \mathrm{~min}$ is negligible. Hence, the kinetic data previously reported are valid in general. However, tyrosinase is known to catalyze a reaction between two substrates, a phenolic compound and oxygen, but the discussion previously described was based on the experiment using mainly L-DOPA as a substrate. As the need arises, $L$-tyrosine was also assayed to see if the inhibitors characterized were effective on monophenolase activity. In either case, the enzyme activity was monitored by dopachrome formation at $475 \mathrm{~nm}$. The assay was carried out in air-saturated aqueous solution and, as a result, oxygen, the other substrate, was disregarded. Hence, we re-examined the enzyme activity by measuring oxygen consumption to examine it from a different point of view. This polarographic method is linked to consecutive spectrum and HPLC analyses and the aforementioned specrophotometric observation was supported [12]. Interestingly, the original yellow color was noted to fade within the first $2 \mathrm{~min}$. Since this intermediate was relatively stable, it was isolated by HPLC and the structure was established as 2-(3,4-dihydroxybenzoyl)-2,4,6-trihydroxy-3(2H)-benzofuranone (6). Thus, quercetin was rapidly oxidized to the corresponding $o$-quinone 7 and subsequent isomerization to $p$-quinone methide type intermediate $8[14,15]$, followed by the addition of water on C-2 yielding the rather stable protocatechuate intermediate 6 (Scheme 1). Although this protocatechuate intermediate $\mathbf{6}$ was relatively stable, it was further oxidized, presumably to the corresponding $\boldsymbol{o}$-quinone $\mathbf{9}$ at a slow rate. This enzymic oxidation was accelerated by the addition of the catalytic amount $(10 \mu \mathrm{M})$ of L-DOPA [12].

Scheme 1. Proposed mechanism for the oxidative degradation of quercetin (1) catalyzed by mushroom tyrosinase.<smiles>C#CC#CC1=CC(=C2Oc3cc(O)cc(O)c3C(=O)C2=O)C=CC1=O</smiles><smiles>O=C(C(=O)c1c(O)cc(O)cc1O)c1ccc(O)c(O)c1</smiles><smiles>CC(C)(C)C1(C)CCCCC1(C)C(=O)c1ccc(O)c(O)c1</smiles>

The experiment was extended to examine the effect of quercetin on the tyrosinase-catalyzed oxidation of $L$-DOPA. The reaction mixture consisting of tyrosinase $(1 \mu \mathrm{g} / \mathrm{mL})$, quercetin $(0.1 \mathrm{mM})$ 
and L-DOPA (0.1 $\mathrm{mM})$ was incubated. The reaction mixture did not show the characteristic absorbance with a maximum at around $475 \mathrm{~nm}$ corresponding to dopaquinone up to $20 \mathrm{~min}$. The original yellow color of reaction mixture was noted to fade shortly and then stayed as nearly colorless approximately up to $20 \mathrm{~min}$. This leads us to believe that quercetin is causing inhibition of DOPA oxidation, as long as the activity is monitored by the spectrophotometric method. Additional evidence was obtained by HPLC analysis of the same reaction medium at $20 \mathrm{~min}$ intervals for $40 \mathrm{~min}$. The result indicates that both quercetin and $L$-DOPA were simultaneously oxidized, presumably to the corresponding o-quinone 7 and dopaquinone (10), respectively. Both intermediates were oxidized further and led to a complex mixture, depending on the relative concentrations of quercetin and $L$-DOPA. The oxidation rate of quercetin with $L$-DOPA was noted to be faster than in the experiment without $L$-DOPA. Moreover, some polar peaks around $t_{\mathrm{R}} 5.0 \mathrm{~min}$ emerged, besides the peak of dapachrome (5), whereas these peaks were not observed on $L$-DOPA oxidation. The oxidation products are a complex mixture of polar compounds and the unstable nature of the intermediates makes their characterization difficult. As long as the enzyme activity was monitored by dopachrome formation at $475 \mathrm{~nm}$, this peak was not detectable up to $20 \mathrm{~min}$. In brief, quercetin was oxidized as a substrate and there was a time lag until the peak of dapachrome become visible and the lag time was lengthened when L-DOPA was increased. Recently, glutathionyl adducts were identified in the incubation experiment with quercetin and glutathione in the presence of peroxidase by LC/MS analysis [15]. Dopaquinone accompanying the oxidation of $L$-DOPA is chemically a highly reactive intermediate and forms adducts with quercetin through a Michael type addition. The initial adduct between dopaquinone and quercetin seemed to be unstable and further converted to a complex mixture. It is evident that quercetin is not an inhibitor but is oxidized as a substrate even without a cofactor and forms adducts. In other words, quercetin (1) is partially oxidized to the colorless intermediate $\mathbf{6}$ and partially forms adducts with dopaquinone (10), and this postulate explains the aforementioned lag time. Thus, dopaquinone is removed from the reaction mixture without being further oxidized to dopachrome (5, Scheme 2). Hence, the inhibitory action of quercetin is based on singly assay system that might prove to be inaccurate while dealing with unstable reaction products $[9,16]$.

Scheme 2. Proposed mechanism for the adduct production with quercetin (1) and dopaquinone (10) in the presence of mushroom tyrosinase.

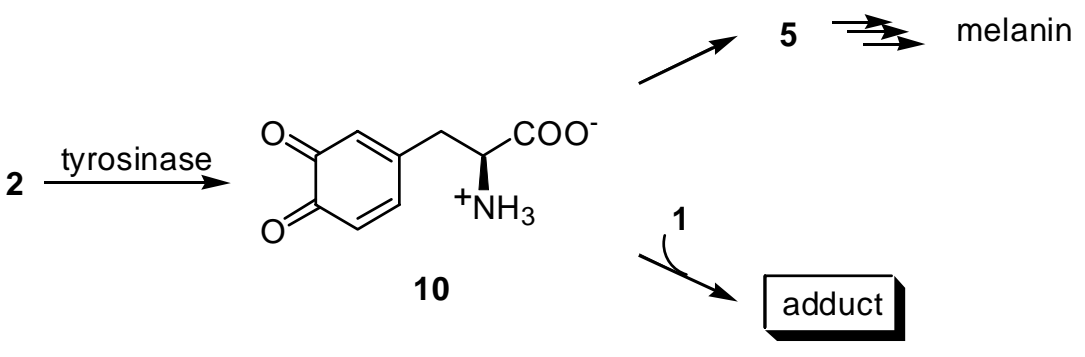

Tyrosinase contains a strongly coupled binuclear copper active site and functions both as a monophenolase and as an $o$-diphenolase [17]. The discussion aforementioned is based on the experiment using $L$-DOPA as a substrate. Therefore, the activity aforementioned is $o$-diphenolase inhibitory activity of tyrosinase. On the other hand, the existence of a lag time is known for the oxidation of monophenol substrates such as L-tyrosine to $L$-DOPA. This lag time can be shortened or 
eliminated by the presence of cofactors, especially o-diphenols such as L-DOPA and catechol. Quercetin eliminated the lag time because this flavonol possesses the catechol moiety in the B-ring. Thus, quercetin acts as a cofactor.

Based on the above conclusion with regards to adduct formation, the experiment was extended to test galangin (11), which is expected to form adducts with dopaquinone without itself being oxidized because its B-ring is unsubstituted. In the same preincubation experiment with galangin, we found that this flavonol was not oxidized even after the addition of a cofactor and remained without any change. An additional experiment was performed by HPLC analysis of the reaction medium consisting of tyrosinase $(1 \mu \mathrm{g} / \mathrm{mL})$, galangin $(0.1 \mathrm{mM})$ and $L$-DOPA $(0.5 \mathrm{mM})$ for $20 \mathrm{~min}$. The peak $\boldsymbol{a}$, identified as galangin, started to diminish gradually, as illustrated in Figure 2. The results suggest that a chemical interaction occurred between galangin and o-dopaquinone, yielding different products than those formed in the absence of galangin. The amount of the dopachrome formed after $30 \mathrm{~min}$ is about $20 \%$ less than the control and this may caused in part by the formation of adducts. On the other hand, the lag time is known for the oxidation of monophenolic substrates as aforementioned. More specifically, galangin significantly suppressed the tyrosinase catalyzed oxidation of L-tyrosine (monophenolase activity).

Figure 2. HPLC analysis of the reaction medium with $100 \mu \mathrm{M}$ of galangin (11) and tyrosinase in presence of $0.5 \mathrm{mM}$ L-DOPA. Sampling time was chosen at 0 min (upper), 5 min (middle), and 20 min (lower), respectively. The HPLC operating condition were as follows: column; Capcell Pak C-18 (Shiseido, Tokyo, Japan), solvent; $40 \% \mathrm{MeCN} / \mathrm{H}_{2} \mathrm{O}$ containing $0.1 \%$ TFA, flow rate; $0.8 \mathrm{~mL} / \mathrm{min}$, detection; UV at $280 \mathrm{~nm}$, injected amount; $20 \mu \mathrm{L}$ from 3-mL assay system.
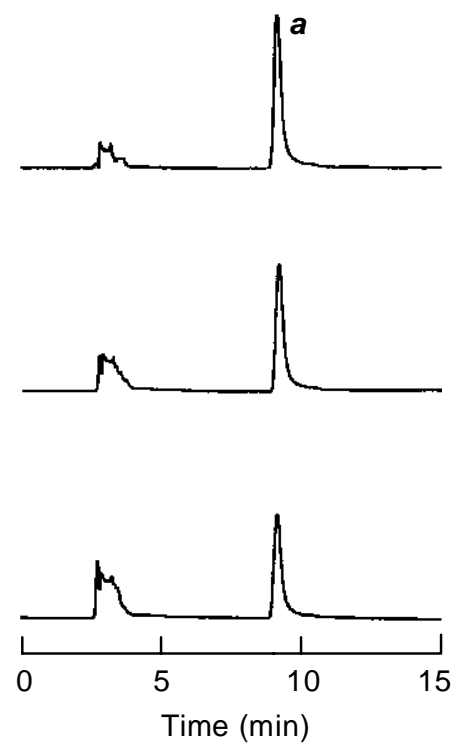

In addition, since the structurally related flavones chrysin (12) and apigenin (13) did not form adducts under the same experimental conditions, it appears that the C-3 hydroxyl group in galangin is involved in the formation of adducts. This conclusion was supported by the additional experiment that showed that the simplest compound of this series, 3-hydroxyflavone (14), as well as 3,5-dihydroxy-flavone (15), 3,7-dihydroxyflavone (16) and 3,4'-dihydroxyflavone (17) also formed 
adducts, but isoquercitrin (3), rutin (4), 5,4'-dihydroxyflavone (18) and naringenin (19) did not. It appears that flavonols form adducts using $L$-DOPA as a substrate as long as their 3-hydroxyl group is free. In connection with this, these flavonols 14-17 may be useful as partial melanin formation inhibitors. However, the observation in the cell-free experiments needs to be carefully considered in living system.

Tyrosinase is a key enzyme in melanin synthetic pathway and therefore its inhibitors are expected to inhibit melanin production. However, there is a gap between the simplified cell free experiments and cellular application. The inhibition of mushroom tyrosinase activity was reported not to correlate with that of cellular tyrosinase or melanin production in cultured melanocytes [18]. The recent report indicates that $o$-phenylphenol, which is known as a depigmenting agent, has little depigmenting action while its metabolite, phenylhydroquinone is a potent depigmenting agent affecting melanocytes [19]. This prompted us to see whether quercetin is oxidized to the corresponding o-quinone 8 in melanocytes and blocks melanin biosynthesis. Hence, the effects of quercetin on melanin synthesis in cultured murine B16-F10 melanoma cells were examined. The initial goal was to test whether quercetin inhibits melanogenesis in melanocytes without affecting cell growth. In this regard, cell viability was determined on the third day for melanocytes using both trypan blue dye exclusion and 3(4,5-dimethylthiazole-2-yl)-2,5-diphenyltetrazolium bromide (MTT) colorimetric assays. The specificity of melanogenesis inhibition was assessed by dividing the melanin content by the number of cells which was determined by trypan blue exclusion. The appropriate concentrations for the preliminary assays performed were selected by microscopic observation. The highest concentration of quercetin tested was $80 \mu \mathrm{M}$. Kojic acid (5-hydroxy-2-hydroxymethyl-4H-pyran-4-one, 20) was also tested as a reference compound. The concentration of quercetin leading to $50 \%$ viable cells lost (IC 50 ) was established as $20 \mu \mathrm{M}$ and almost complete lethality was observed at $80 \mu \mathrm{M}$ (Figure 3a). The number of viable cells decreased in a dose-dependent manner at concentrations higher than $5 \mu \mathrm{M}$. On the other hand, the amount of total melanin content showed no significant decrease until $20 \mu \mathrm{M}$ and its decrease rates at 40 and $80 \mu \mathrm{M}$ were less than those of the number of viable cells (Figure $3 \mathrm{~b}$ ), indicating that quercetin enhanced the cellular melanin production at concentrations higher than $5 \mu \mathrm{M}$ (Figure 3c). The result observed is similar to the previous report that quercetin enhanced melanogenesis in human melanoma cells and in normal human melanocytes by increasing the activity and synthesis of tyrosinase [20]. But, it should be noted that dramatic increase in the cellular melanin content at concentrations higher than $20 \mu \mathrm{M}$ might be a consequence of cell death induced by cytotoxic concentrations of quercetin [21], at least at part, rather than due to a direct effect of quercetin. Rutin showed neither cytotoxicity nor suppressed melanin formation up to $200 \mu \mathrm{M}$. In the case of kojic acid, melanin production in the cultured cells was suppressed in a dose-dependent manner without affecting cell growth up to $1 \mathrm{mM}$.

The precise explanation of the observed cytotoxicity of quercetin still remains unknown though there are many possibilities. Quercetin presumably enters into cells by passive diffusion across the membrane. Once inside cells, quercetin may be oxidized in part to the corresponding quinone-methide 7 and this chemically highly reactive quinone-methide binds with various intracellular materials similar to those previously described [22,23]. However, being oxidized to reactive intermediates may not be the case as long as murine B16-F10 melanoma cells are concerned because galangin (11), 
chrysin (12) and 7-hydroxyflavone (21) whose B-ring is unsubstituted still showed almost comparative potent cytotoxicity, although rutin did not show any cytotoxicity.

Figure 3. (a) Viabilities of B16-F10 melanoma cells following treatment with quercetin (6) for $72 \mathrm{~h}$; data are expressed as percentage of the number of viable cells observed with the control, and each column represents the mean \pm S. D. of at least 6 determinations. (b) Total melanin content in B16 melanoma cells following treatment with quercetin for $72 \mathrm{~h}$; data are expressed as percentage of melanin content per well observed with the control, and each column represents the mean \pm S. D. of 4 determinations. (c) Cellular melanin content in B16 melanoma cells following treatment with quercetin for $72 \mathrm{~h}$ measured as percentage of melanin content per cell observed with the control, and each column represents the mean \pm S. D. of 4 determinations. The statistical significance of differences was evaluated using Student's or Welch's $t$-test. Significantly different from the control value: ${ }^{*} p<0.05$, $* * p<0.01$.

a
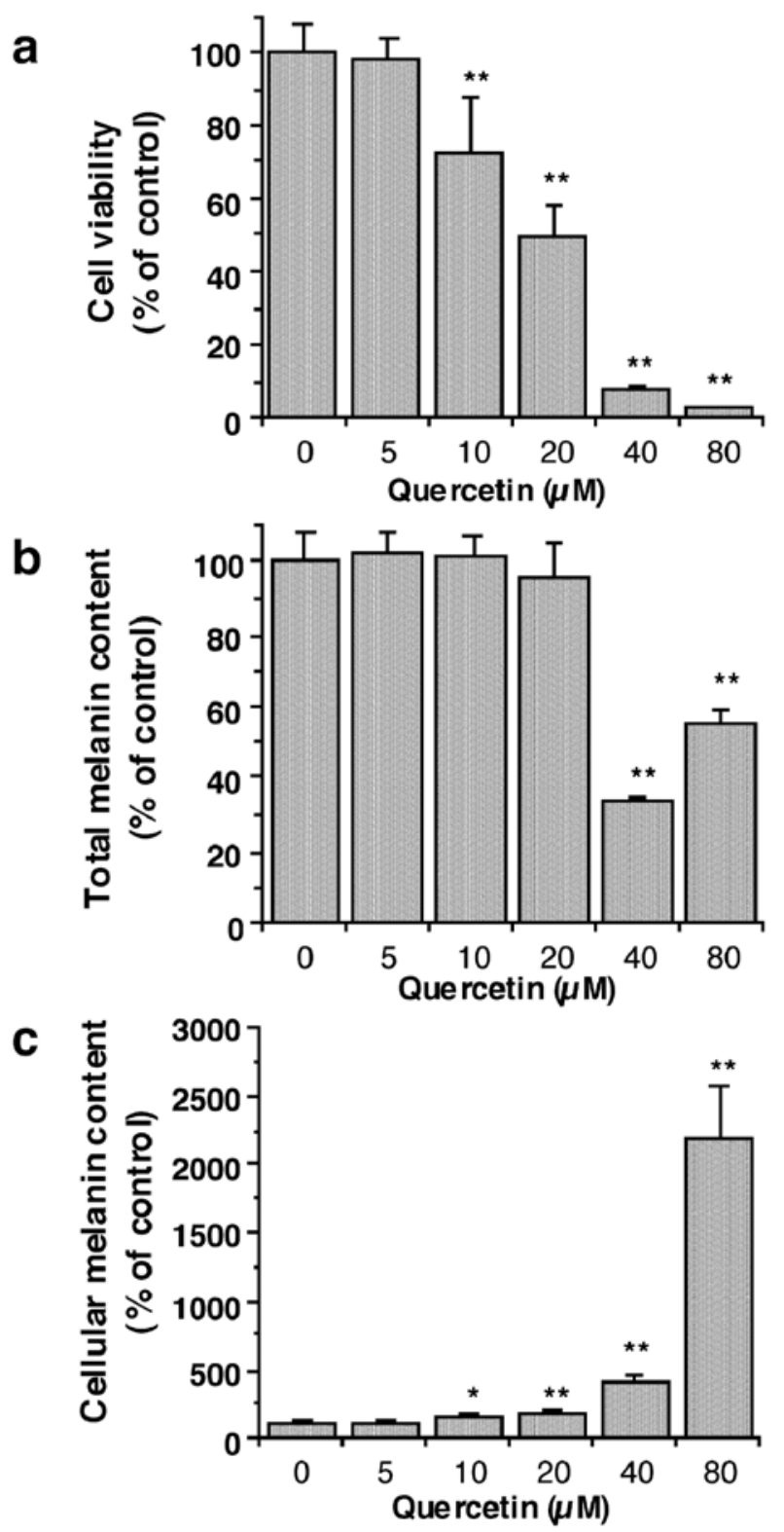
Taken altogether, it seems that flavone skeleton may be prerequisite to elicit the activity. For example, chrysin was reported to interfere with steroid synthesis and metabolism [24,25]. The common observation with flavonoids, melanogenesis enhancing activity and cytotoxicity, may not be explained by a single defined action but involves multifunction.

The effect of quercetin on murine B16-F10 melanoma cells was previously reported, but cell viability was examined using only MTT colorimetric assays [26]. It should be noted that both trypan blue dye exclusion and MTT colorimetric assays for cell viability assays provide essentially the same results. In the case of quercetin, however, MTT colorimetric assay did not show noticeable change up to $20 \mu \mathrm{M}$, which seemingly indicates that quercetin did not show any lethality up to this concentration. An analogous observation with quercetin was previously explained by its reducing ability of MTT even without living cells [27]. However, the similar results were also observed with both galangin and chrysin, but neither flavonoid had reducing ability of MTT. The disadvantage of the MTT colorimetric assay is known that damaged mitochondria may reduce MTT to formazan [28]. The precise explanation for the conflicting result observed remains to be clarified.

The results obtained in the current experiment were observed in a test tube condition, but biological significance of quercetin tested as a melanin synthesis inhibitor in living systems is largely unknown. The relevance of the in vitro experiments in simplified systems to living system should be carefully considered. It is apparent that the antimelanogenic action is not simply to inhibit tyrosinase but involves more complex biochemical reactions. Further evaluation needs to be investigated not only from one aspect, but also from a whole and dynamic perspective. The majority of cancer patients who succumb to their disease die from metastasis. Metastasis is a sequential process in which tumor cells detach from the primary growth, invade through the surrounding host tissue into the circulation and subsequently disseminate to distant organs, where they arrest, extravasate and proliferate to form metastatic foci [29]. The B16-F10 cell line was shown to metastasize to lungs when injected through the lateral tail vain [30], and was reported to be a model to study lung metastasis [31]. Quercetin and rutin were previously tested for the inhibition of lung metastasis induced by B16-F10 melanoma cells in mice. Oral administration of rutin at concentrations of $200 \mathrm{nmol} / \mathrm{kg}$ body weight was found to inhibit the lung tumor nodule formation but quercetin did not [32].

\section{Experimental}

\section{General}

Quercetin $2 \mathrm{H}_{2} \mathrm{O}$, L-Tyrosine and dimethyl sulfoxide (DMSO) were purchased from Sigma Chemical Co. (St. Louis, MO). L-DOPA was obtained from Aldrich Chemicals Co. (Milwaukee, WI). 3-Hydroxyflavone, 3,5-dihydroxyflavone, 3,7-dihydroxyflavone, 3,4'-dihydroxyflavone, isoquercitrin, rutin, 5,4'-dihydroxyflavone, and naringenin were purchased from INDOFINE Chemical Company, Hillsborough, NJ).

\section{Enzyme Assay}

The mushroom tyrosinase (EC 1.14.18.1) used for the bioassay was purchased from Sigma Chemical Co. and was purified by anion-exchange chromatography using DEAE-Sepharose Fast Flow 
(Pharmacia, Uppsala, Sweden) as previously described [33]. Oxygen consumption was measured by a Clark style electrode and an oxygraph (YSI-53) equipped with a water-jacketed chamber (Yellow Springs Instrument Co., Yellow Springs, $\mathrm{OH}$ ) maintained at $30{ }^{\circ} \mathrm{C}$. Calibration of an oxygen electrode was performed using 4-tert-butylcatechol and excess tyrosinase according to the previous report [34]. Absorption measurements were recorded by a SpectraMAX Plus spectrophotometer (Molecular Devices, Sunnyvale, CA) at $30^{\circ} \mathrm{C}$. All samples were first dissolved in DMSO at $30 \mathrm{mM}$ and used for the experiment with dilution. The final concentration of DMSO in the test solution is always $3.3 \%$. For obtaining data of absorbance increment at $475 \mathrm{~nm}$ and oxygen consumption, an inhibitor solution $(0.1 \mathrm{~mL})$ was mixed with $0.25 \mathrm{M}$ sodium phosphate buffer $(\mathrm{pH} 6.8,0.6 \mathrm{~mL})$ and water $(2.2 \mathrm{~mL})$. Then, the $0.05 \mathrm{M}$ sodium phosphate buffer solution $(\mathrm{pH} 6.8,0.1 \mathrm{~mL})$ of tyrosinase $(30 \mu \mathrm{g} / \mathrm{mL}$ ) was added. When $L$-tyrosine was used as monophenol substrate, instead of $2.2 \mathrm{~mL}$ of water, $0.3 \mathrm{~mL}$ of $1.25 \mathrm{mM}$ $L$-tyrosine solution and $1.9 \mathrm{~mL}$ of water were added. In the experiment using cofactor, DOPA (6 $\mu \mathrm{L}$, $5 \mathrm{mM}$ ) was added 5 min after the enzymatic reaction started. Scan speed was selected as 2 min with 30 $\mathrm{s}$ intervals for obtaining consecutive spectra (220 to $500 \mathrm{~nm}$ ). The assays were performed in triplicate on separate occasions.

\section{HPLC Analysis}

The analysis was performed on an EYELA LPG-1000 with an EYELA UV-7000 detector (EYELA, Tokyo) and Capcell Pak C-18 column (5 $\mu \mathrm{m}, 4.6 \times 250 \mathrm{~mm}$, Shiseido, Tokyo) [35]. In general, the operating conditions were as follows: solvent; $2.5 \% \mathrm{MeCN} / \mathrm{H}_{2} \mathrm{O}$ containing $0.1 \% \mathrm{TFA}$, flow rate; $0.8 \mathrm{~mL} / \mathrm{mim}$, detection; $\mathrm{UV}$ at $280 \mathrm{~nm}$, injected amount; $20 \mu \mathrm{L}$ from 3-mL assay system. The preparative HPLC was performed using an Econosil C18 column $(10 \mu \mathrm{m}, 10 \times 250 \mathrm{~mm}$, Alltech, Deerfield). The flow rate and detected wavelength were adjusted at $5 \mathrm{~mL} / \mathrm{min}$ and $280 \mathrm{~nm}$.

\section{Cell Culture}

B16-F10 mouse melanoma cells (ATCC CRL-6475) were cultured in continuous log phase growth in Dulbecco's modified Eagle’s medium (DMEM) containing 10\% FBS. Cells were seeded in 96-well plates (2500 cells/well) and incubated at $37{ }^{\circ} \mathrm{C}$ in $5 \% \mathrm{CO}_{2}$ for about 24 hours before arbutin and/or ascorbic acid treatment. When both arbutin and ascorbic acid were applied, cells were first treated with ascorbic acid, followed immediately by arbutin treatment. Each chemical combination was applied in duplicate with a final concentration of $0.1 \%$ DMSO, and treated cells were cultured for $72 \mathrm{~h}$ before assays.

\section{Cell Viability Assays}

Cell viability was determined by trypan blue exclusion using a hemocytometer. After overnight incubation of cells, viability was also determined by the MTT cell proliferation assay (ATCC 30-1010K). Both bioassays basically obtained the same results but the concentration leading to 50\% viable cells lost $\left(\mathrm{IC}_{50}\right)$ was established by trypan blue assay. The appropriate concentrations of the test 
chemicals for the following melanin assay were selected by microscopic observation using a Nikon Diaphoto TMD.

\section{Melanin Assay}

The melanin content was determined as previously described [36, 37] with minor modifications. Cells were washed with PBS, harvested by trypsinization, and centrifuged for 10 minutes at $1500 \mathrm{~g}$. The cell pellets were then dissolved in $1.4 \mathrm{M} \mathrm{NaOH}$ containing 14\% DMSO during 2 hours incubation at $80^{\circ} \mathrm{C}$. Melanin content was measured at $475 \mathrm{~nm}$ using a SpectraMax Plus spectrophotometer.

\section{Acknowledgements}

The authors are indebted to Ms. I. Hori for performing the enzyme assay at the earlier stage of the work. T.N. thanks Japan Society for the Promotion of Science for financial support during his study at UC Berkeley.

\section{References}

1. Holme, S. A.; Varma, S.; Chowdhury, M. M.; Roberts, D. L. Audit of a melanoma screening day in the U.K.: clinical results, participant satisfaction and perceived value. Br. J. Dermatol. 2001, 145, 784-788.

2. Prezioso, J. A.; Epperly, M. W.; Wang, N.; Bloomer, W. D. Effects of tyrosinase activity on the cytotoxicity of 4-S-cysteaminylphenol and $\mathrm{N}$-acetyl-4-S-cysteaminylphenol in melanoma cells. Cancer Lett. 1992, 63, 73-79.

3. Xu, Y.; Stokes, A. H.; Freeman, W. M.; Kumer, S. C.; Vogt, B. A.; Vrana, K. E. Tyrosinase mRNA is expressed in human substantia nigra. Mol. Brain Res. 1997, 45, 159-162.

4. Kubo, I.; Kinst-Hori, I.; Ishiguro, K.; Chaudhuri, S. K.; Sanchez, Y.; Ogura, T. Tyrosinase inhibitory flavonoids from Heterotheca inuloides and their structural functions. Bioorg. Med. Chem. Lett. 1994, 4, 1443-1446.

5. Kubo, I.; Kinst-Hori, I.; Chaudhuri, S. K.; Sanchez, Y.; Ogura, T. Flavonols from Heterotheca inuloides. Tyrosinase inhibitory activity and structural criteria. Bioorg. Med. Chem. 2000, 8, 1585-1591.

6. Matinez, M. Catálogo de Nombres Vulgares y Cientificos de Plantas Mexicanas; Fondo de Cultura Economica: Mexico, 1984; pp. 145-146.

7. Matsuda, H.; Morikawa, T.; Ando, S.; Toguchida, I.; Yoshikawa, M. Structural requirements of flavonoids for nitric oxide production inhibitory activity and mechanism of action. Bioorg. Med. Chem. 2003, 11, 1995-2000.

8. Nagatsu, A., Zhang, H. L., Mizukami, H., Sakakibara, J., Tokuda, H., Nishino, H. Tyrosinase inhibitory and anti-tumor promoting activities of compounds isolated from safflower (Carthamus tinctorius L.) and cotton (Gossypium hirsutum L.) oil cakes. Nat. Prod. Lett. 2000, 14, 153-158.

9. Xie, L. P.; Chen, Q. Y.; Huang, H.; Wang, H. Z.; Zhang, R. Q. Inhibitory effects of some flavonoids on the activity of mushroom tyrosinase. Biochemistry (Moscow) 2003, 68, 487-491. 
10. Jeong, C. H.; Shim, K. H. Tyrosinase inhibitor isolated from the leaves of Zanthoxylum piperitum. Biosci. Biotechnol. Biochem. 2004, 68, 1984-1987.

11. Kubo, I.; Kinst-Hori, I. Flavonols from saffron flower: Tyrosinase inhibitory activity and inhibition mechanism. J. Agric. Food Chem. 1999, 47, 4121-4125.

12. Kubo, I.; Nihei, K.; Shimizu, K. Oxidation products of quercetin by mushroom tyrosinase. Bioorg. Med. Chem. 2004, 12, 5343-5347.

13. Mayer, A. M. Polyphenol oxidases in plants - Recent progress. Phytochemistry 1987, 26, 11-20.

14. Boersma, M. G.; Vervoort , J.; Szymusiak, H.; Lemanska, K.; Tyrakowska, B.; Cenas, N.; SeguraAguilar, J.; Rietjens, I. M. Regioselectivity and reversibility of the glutathione conjugation of quercetin quinone methide. Chem Res Toxicol. 2000, 13, 185-191.

15. Awad, H. M.; Boersma, M. G.; Vervoort, J.; Rietjens, I. M. C. M. Peroxidase-catalyzed formation of quercetin quinone methide-glutathione adducts. Arch. Biochem. Biophys. 2000, 378, 224-233.

16. Chen, Q. X.; Kubo, I. Kinetics of tyrosinase inhibition by quercetin. J. Agric. Food Chem. 2002, 50, 4108-4112.

17. Sánchez-Ferrer, A.; Rodríguez-López, J. N.; Garcia-Cánovas, F.; García-Carmona, F. Tyrosinase: A comprehensive review of its mechanism. Biochem. Biophys. Acta 1995, 1247, 1-11.

18. Maeda, K.; Fukuda, M. Arbutin: Mechanism of its depigmenting action in human melanocyte culture. J. Pharm. Exp. Therap. 1996, 276, 765-769.

19. Tayama, K.; Takahama, M. Depigmenting action of phenylhydroquinone, an o-phenylphenol metabolite, on the skin of JY-4 black guinea-pigs. Pigment Cell Res. 2002, 15, 447-453.

20. Nagata, H.; Takekoshi, S.; Takeyama, R.; Homma, T. Quercetin enhances melanogenesis by increasing the activity and synthesis of tyrosinase in human melanoma cells and in normal human melanocytes. Pigment Cell Res. 2004, 17, 66-73.

21. Metodiewa, D.; Jaiswal, A. K.; Cenas, N.; Dickancaite, E.; Segura-Aguilar, J. Quercetin may act as a cytotoxic prooxidant after its metabolic activation to semiquinone and quinoid product. Free Radic. Biol. Med. 1999, 26, 107-116.

22. Bolton, J. L.; Trush, M. A.; Penning, T. M.; Dryhurst, G. Monks, T. J. Role of quinones in toxicology. Chem. Res. Toxicol. 2000, 13, 135-160.

23. Kaldas, M. I.; Walle, U. K.; van der Woude, H.; McMillan, J. M.; Walle, T. Covalent binding of the flavonoid quercetin to human serum albumin. J. Agric. Food Chem. 2005, 53, 4194-4197.

24. Le Bail, J. C.; Laroche, T.; Marre-Fournier, F.; Habrioux, G. Aromatase and 17ß-hydroxysteroid dehydrogenase inhibition by flavonoids. Cancer Lett. 1998, 133, 101-106.

25. Sanderson, J. T.; Hordijk, J.; Denison, M. S.; Springsteel, M. F.; Nantz, M. H.; van den Berg, M. Induction and inhibition of aromatase (CYP19) activity by natural and synthetic flavonoid compounds in H295R human adrenocortica carciboma cells. Toxicol. Sci. 2004, 82, 70-79.

26. Yáñez, J.; Vicente, V.; Alcaraz, M.; Castillo, J.; Benavente-Garcćia, O.; Canteras, M.; Teruel, J. A. L. Cytotoxicity and antiproliferative activities of several phenolic compounds against three melanocytes cell lines: relationship between structure and activity. Nutr. Cancer 2004, 49, 192199.

27. Peng, L.; Wang, B.; Ren, P. Reduction of MTT by flavonoids in the absence of cells. Colloids Surf., B 2005, 45, 108-111. 
28. Mueller, H.; Kassack, M.; Wiese, M. Comparison of the usefulness of the MTT, ATP, and calcein assays to predict the potency of cytotoxic agents in various human cancer cell lines. J. Biomolec. Screen. 2004, 9, 506-515.

29. Fidler I. J. Selection of successive tumor lines for metastasis. Nature 1973, 242, 148-149.

30. Poste, G.; Fidler, I. J. The pathogenesis of cancer metastasis. Nature 1980, 283, 139-146.

31. Eisenthal, A.; Cameron, R. B.; Uppenkamp, I.; Resenberg, S. A. Effect of combined therapy with lymphokine activated killer cells, interleukin 2 and specific monoclonal antibody on established B16 melanoma lung metastasis. Cancer Res. 1988, 48, 7140-7145.

32. Menon, L. G.; Kuttan, R.; Kuttan, G. Inhibition of lung metastasis in mice induced by B16F10 melanoma cells by polyphenolic compounds. Cancer Lett. 1995, 95, 221-225.

33. Espín, J. C.; Wichers, H. J. Slow-binding inhibition of mushroom (Agaricus bisporus) tyrosinase isoforms by tropolone. J. Agric. Food Chem. 1999, 47, 2638-2644.

34. Rodríguez-López, J. N.; Ros-Martínez, J. R.; Varón, R.; García-Cánovas, F. Calibration of a clark-type oxygen electrode by tyrosinase-catalyzed oxidation of 4-tert-butylcatechol. Anal. Biochem. 1992, 202, 356-360.

35. Nihei, K.; Kubo, I. Identification of oxidation product of arbutin in mushroom tyrosinase assay system. Bioorg. Med. Chem. Lett. 2003, 13, 2409-2412.

36. Kageyama, A.; Oka, M.; Okada, T.; Nakamura, S.; Ueyama, T.; Saito, N.; Hearing, V. J.; Ichihashi, M.; Nishigori, C. Down-regulation of melanogenesis by phospholipase D2 through ubiquitin proteasome-mediated degradation of tyrosinase. J. Biol. Chem. 2004, 279, 27774-27780.

37. Venkatasamy, R.; Faas, L.; Young, A. R.; Raman, A.; Hider, R. C. Effects of piperine analogues on stimulation of melanocyte proliferation and melanocyte differentiation. Bioorg. Med. Chem. 2004, 12, 1905-1920.

Sample Availability: Contact the authors.

(c) 2007 by MDPI (http://www.mdpi.org). Reproduction is permitted for noncommercial purposes. 